\title{
Jeune syndrome: description of 13 cases and a proposal for follow-up protocol
}

\author{
J. de Vries • J. L. Yntema • C. E. van Die • N. Crama • \\ E. A. M. Cornelissen • B. C. J. Hamel
}

Received: 5 January 2009 /Accepted: 27 April 2009 / Published online: 10 May 2009

(C) The Author(s) 2009. This article is published with open access at Springerlink.com

\begin{abstract}
Jeune syndrome (asphyxiating thoracic dystrophy, ATD) is a rare autosomal recessive skeletal dysplasia characterized by a small, narrow chest and variable limb shortness with a considerable neonatal mortality as a result of respiratory distress. Renal, hepatic, pancreatic and ocular complications may occur later in life. We describe 13 cases with ages ranging from 9 months to 22 years. Most patients experienced respiratory problems in the first years of their life, three died, one experienced renal complications, and one had hepatic problems. With age, the thoracic malformation tends to become less pronounced and the respiratory problems decrease. The prognosis of ATD seems better than described in literature and in our opinion this justifies long term intensive treatment in the first years. We also propose a follow-up protocol for patients with ATD.
\end{abstract}

Keywords Jeune syndrome - Asphyxiating thoracic dystrophy $\cdot$ Survival $\cdot$ Follow-up protocol

J. de Vries ·J. L. Yntema • E. A. M. Cornelissen

Department of Paediatrics,

Radboud University Nijmegen Medical Centre,

PO Box 9101, 6500 HB, Nijmegen, The Netherlands

C. E. van Die

Department of Radiology,

Radboud University Nijmegen Medical Centre,

PO Box 9101, 6500 HB, Nijmegen, The Netherlands

N. Crama

Department of Ophthalmology,

Radboud University Nijmegen Medical Centre,

PO Box 9101, 6500 HB, Nijmegen, The Netherlands

B. C. J. Hamel $(\bowtie)$

Department of Human Genetics,

Radboud University Nijmegen Medical Centre,

PO Box 9101, 6500 HB, Nijmegen, The Netherlands

e-mail: b.hamel@antrg.umcn.nl

\author{
Abbreviations \\ AF alkaline phosphatase \\ ALAT alanine-aminotransferase \\ ASAT aspartate-aminotransferase \\ CAPD continuous ambulant peritoneal dialysis \\ CMV cytomegaly virus \\ CTR cardio-thoracic ratio \\ EBV Epstein-Barr virus \\ FVC forced vital capacity \\ FEV1 forced expiratory volume in one second \\ $\gamma$-GT gamma-glutamyl transferase \\ LD lactate dehydrogenase
}

\section{Introduction}

Asphyxiating thoracic dystrophy (ATD; OMIM 208500), also known as Jeune syndrome, is a rare autosomal recessive skeletal dysplasia with multi-organ involvement. It was first described in 1955 by Jeune et al. [24]. Diagnosis is based on clinical and radiographic findings. Clinically, ATD is characterized by a small, narrow chest and variable limb shortness. Associated congenital abnormalities are postaxial polydactyly of both hands and/or feet (20\%) [21]. Typical radiographic findings include a narrow, bell-shaped thorax with short, horizontally oriented ribs and irregular costochondral junctions, elevated clavicles, short iliac bones with a typical trident appearance of the acetabula, relatively short and wide long bones of the extremities, and hypoplastic phalanges of both hands and feet with coneshaped epiphyses $[4,9,16,21,22,25,33]$. The small, narrow thorax often results in respiratory distress and recurrent respiratory infections in the neonatal period and infancy. Often (60-80\%), the outcome of ATD is said to be 
fatal in early childhood [2, 29-31]. Patients surviving infancy may develop progressive renal failure later in life [21]. Liver, pancreas and retinal abnormalities have also been described [1, 3, 7, 23, 26, 27, 38, 40-42]. Treatment of ATD is symptomatic. The thoracic malformation tends to become less severe with age, resulting in less respiratory problems $[16,20-22,30]$. The inheritance of ATD is autosomal recessive. A locus has been identified on chromosome 15q13 [29], while recently, mutations were found in the IFT80 gene, encoding an intraflagellar protein, in a small subset of ATD patients, who did not have extraskeletal manifestations [5]. Antenatal examination is possible by ultrasound, but the precise diagnosis is very difficult or impossible. Key factors in the prenatal diagnosis are an abnormal small thorax, short limbs, polyhydramnios, and unidentifiable fetal respiratory movements [8, 13, 43].

In this article, we describe 13 patients with ATD and we propose a follow-up protocol.

\section{Materials and methods}

\section{Literature}

The following databases were searched: PubMed and Online Mendelian Inheritance in Man (OMIM), using key words "Jeune syndrome" or "asphyxiating thoracic dystrophy".

\section{Patients}

We included all patients diagnosed with ATD at the Radboud University Nijmegen Medical Centre in Nijmegen. Diagnoses were based on the presence of clinical findings, like a small, narrow chest and variable limb shortness and radiographic findings, like narrow, bellshaped thorax with short, horizontally oriented ribs, irregular costochondral junctions and elevated clavicles, short iliac bones with a typical trident appearance of the acetabula, and if available, relatively short and wide long bones of the extremities and hypoplastic phalanges of both hands and feet. We identified 13 patients from 11 families, five females and eight males, ages ranging from 9 months to 22 years, of who three died. Hospital charts were reviewed retrospectively. Data collected from these charts included information about hospital admissions, lung function tests, laboratory data and radiographic findings. All 11 living patients (case 13 died at the end of the study) were examined using the same protocol consisting of physical examination, including several anthropometric measurements, chest radiograph, abdominal ultrasound, spirometry, expert ophthalmic examination and blood and $24 \mathrm{~h}$ collected urine analysis. A summary of the clinical and radiographic data is given in Table 1. In all probands except case 9 and 13, IFT80 mutation analysis was performed.

\section{Case reports}

Case 1

Female, 22 years old, the first born to healthy, unrelated Dutch parents. She has one healthy sibling. At the age of 1 year she was evaluated because of growth failure, abnormal chest shape and limb shortness. Skeletal radiographs showed a small, narrow thorax, brachydactyly of the fingers, short and broad diaphyses, and wide metaphyses of the arms and legs, and short iliac bones with spiky protrusions. There was no history of respiratory difficulties. At 3 years of age she was admitted because of a respiratory infection. Blood gas revealed a metabolic acidose, serum creatinine was elevated, urinalysis showed proteinuria and her blood pressure was 200/170 $\mathrm{mmHg}$. Her renal function deteriorated (serum creatinine $422 \mu \mathrm{mol} / 1$, ureum $16.8 \mathrm{mmol} / \mathrm{l}$ ) and at the age of 4 years CAPD was started. A renal transplant was performed when she was 5 years old and 5 weeks later bilateral nephrectomy was performed because of persistent hypertension. At the age of 12 years she developed progressive renal failure, as a result of chronic rejection, and she was transplanted for a second time. Until now, her renal function remained stable. Ophthalmic examination showed narrow blood vessels without clinical problems. At the age of 22 years she is living independently and working as a nurse with mildly impaired exercise tolerance. Physical examination at the age of 22 years showed a height below the third centile, a sitting height/height ratio above the 97th centile, a chest circumference below the third centile, a hand length below the third centile and a foot length below the third centile. The chest radiograph showed an abnormal position of both ribs and claviculae with a CTR of 0.53 (reference $<0.50$; [28]). Pathological examination of the native kidneys showed that most of the glomeruli were totally sclerotic and the remainder showed capillary collapse. Periglomular fibrosis, tubular atrophy and dilatation with interstitial lymphocyte infiltration were seen.

\section{Case 2}

Female, 19 years old, born at term as the third of five children to healthy consanguineous (second cousins) Dutch parents. Birth weight was $3,880 \mathrm{~g}$ (75-90th centile). Physical examination revealed a narrow chest and her liver was palpated $5 \mathrm{~cm}$ below the right costal margin. Intubation was necessary because of severe respiratory distress and she was ventilated for a month. During that time, she had several respiratory 


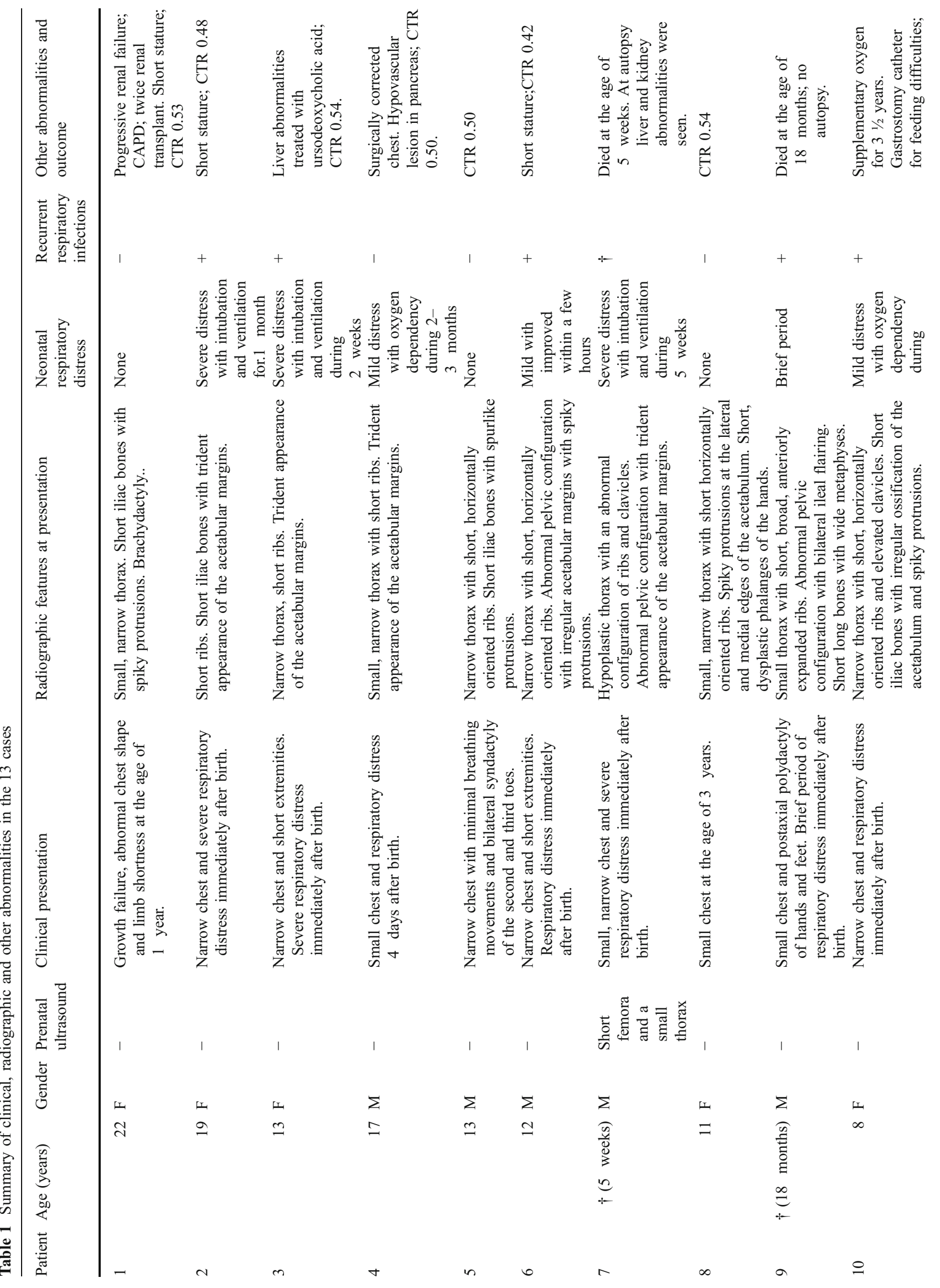




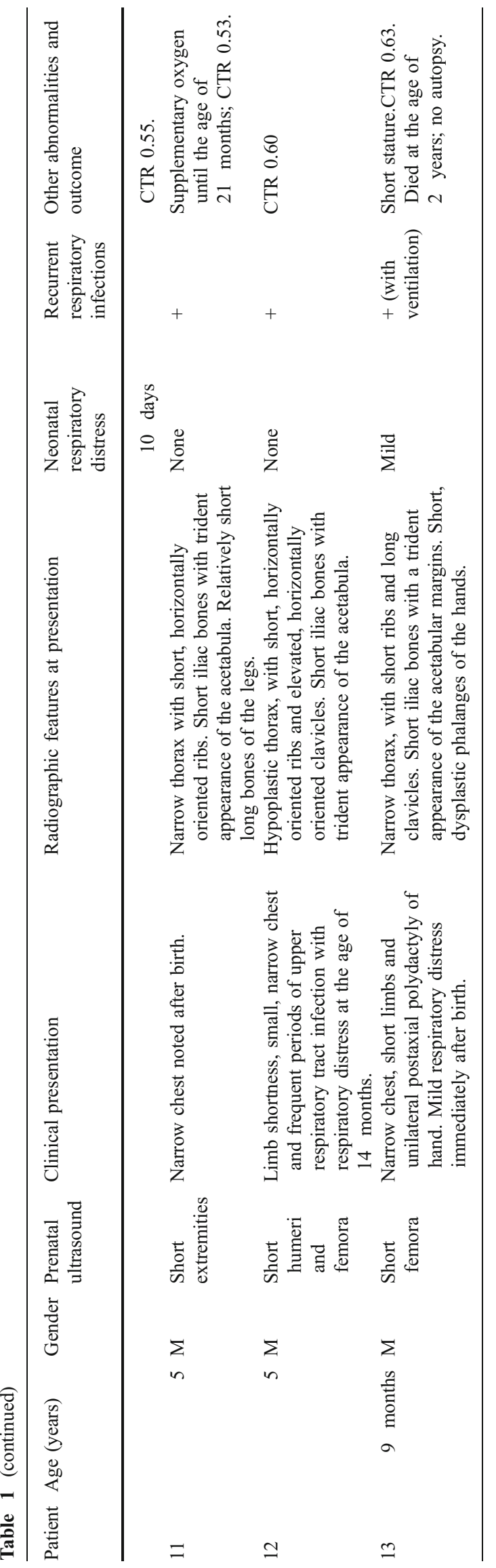

infections. Skeletal radiographs showed short ribs, short iliac bones with a typical trident appearance of the acetabular margins, and mildly shortened humeral bones. Cardiac ultrasound, ophthalmic examination, and repeated abdominal ultrasound revealed no abnormalities. At the age of 19 years, she has a normal exercise tolerance and she is working as a nurse. Physical examination at the age of 19 years showed a height below the third centile, a sitting height/height ratio on the 97th centile, a chest circumference on the 25 th centile and a hand and foot length below the third centile. The chest radiograph showed a narrow thorax with elevated clavicles and a CTR of 0.48 .

\section{Case 3}

Female, 13 years old, sister of case 2, born at term as the last and fifth child. At birth, her weight was $3,780 \mathrm{~g}$ (7590th centile). Physical examination revealed a narrow chest and short extremities. Immediately after birth, she suffered from severe respiratory distress; she was intubated and ventilated for 2 weeks. Skeletal radiographs showed a narrow thorax with a CTR of 0.64 , short ribs with bulbous ends, a typical trident appearance of the acetabular margins and apparently normal bones of arms and legs. Ophthalmic examination and abdominal ultrasound revealed no abnormalities. During her first year, she was readmitted several times because of respiratory exacerbation during respiratory infections. With diuretic therapy, her pulmonary condition stabilized. She needed supplementary oxygen for 6 months. Diuretic therapy was continued until the age of 2 years. At the age of 10 years, she developed a slight scoliosis, for which she was treated with a brace. During routine follow-up at 12 years of age elevated liver enzymes were found. Except for obesity there were no abnormal signs and symptoms. The liver was palpated $2 \mathrm{~cm}$ below the right costal margin. Tests for EBV, CMV, hepatitis A, B, and polymerase chain reaction on hepatitis $\mathrm{C}$ were all negative. Antismooth muscle and antireticulum autoantibodies were not found. Abdominal ultrasonography showed a normal hepatic structure, normal biliary tract, and normal portal flow pattern. Because she was in good health, at that time no further diagnostic procedures were done. Follow-up ultrasonography after 1 year revealed irregularly increased parenchymatous density. Liver and spleen were not enlarged and the abdomen was not painful on palpation. A liver biopsy revealed inflammation of the portal triangles, predominantly eosinophilic, and mild portoportal fibrosis without involvement of the bile canaliculi. Ursodeoxycholic acid was prescribed (600 $\mathrm{mg} / \mathrm{m}^{2} /$ day).

Her height was on the tenth centile, sitting height/height ratio above the 97 th centile, chest circumference on the 
75th centile, hand length on the 50th centile, and foot length between the 25th and 50th centile. The chest radiograph showed a narrow thorax with horizontally oriented clavicles, a short sternum and a CTR of 0.54.

\section{Case 4}

Male, 17 years old, born at term as the second and last child to healthy, unrelated Dutch parents. His birth weight was $4,370 \mathrm{~g}$ ( $>97$ th centile). Physical examination revealed a small chest, but no other abnormalities. He was discharged the same day. He remained well for 4 days, but then he developed respiratory distress and was readmitted. Skeletal radiographs showed a small, narrow thorax with short, broad ribs, a typical trident appearance of the acetabular margins and apparently normal bones of hand and arm. He was discharged at the age of 1 month, oxygen dependent, which he remained for about 1-2 months after discharge. At the age of 6.5 years his chest was surgically corrected, without any complications. At 14 years of age, routine abdominal ultrasound showed a rounded mass in the pancreas (diameter $1 \mathrm{~cm}$ ). Magnetic Resonance cholangiopancreaticography (MRCP) with gadolinium enhancement showed a fluid-rich, hypovascular lesion of 1.0 by $1.2 \mathrm{~cm}$. During the following 3 years there was no change in the diameter of the lesion. Ophthalmic examination showed no abnormalities. At the age of 17, he has a mildly impaired exercise tolerance. Physical examination at the age of 17 years showed a height on the 50 th centile, a sitting height/height ratio on the 97 th centile, a chest circumference between the 50th and 75 th centile, a hand length between the 75th and 97th centile and a foot length above the 97th centile. The chest radiographs showed a thoracic scoliosis and a CTR of 0.50 .

\section{Case 5}

Male, 13 years old, born at term by cesarean section because of an abnormal position, as the first of two children of healthy, unrelated Dutch parents. His birth weight was $2,885 \mathrm{~g}$ (tenth centile). A narrow chest with minimal breathing movements and bilateral syndactyly of the second and third toes were seen. Skeletal radiographs showed a narrow thorax with short, horizontally oriented ribs, an abnormal pelvic configuration with short iliac bones with spurlike protrusions and short metacarpals and distal phalanges. Ophthalmic examination and abdominal ultrasound revealed no abnormalities. He experienced no severe respiratory problems during infancy and childhood. At the age of 13 , he is doing well in school (secondary education) and he has a normal exercise tolerance. Physical examination at the age of 13 years showed a height between the 25th and 50th centile, a sitting height/height ratio on the 90th centile, a chest circumference between the tenth and 25th centile, a hand length between the 25th and 50th centile and a foot length between the tenth and 25 th centile. The chest radiograph showed a narrow thorax and a CTR of 0.50 .

Case 6

Male, 12 years old, born at term as the fourth of five children to healthy, unrelated Dutch parents. At birth weight was $3,150 \mathrm{~g}$ (10-25th centile). After birth, he developed respiratory distress. He was noted to have a narrow, 'bell-shaped' chest and short extremities. His respiratory condition improved within hours after birth. Skeletal radiographs showed a narrow, bell-shaped thorax with short, horizontally oriented and anteriorly expanded ribs and a CTR of 0.62 , an abnormal pelvic configuration with irregular acetabular margins with spiky protrusions and apparently normal bones of arms and legs. Ophthalmic examination and abdominal ultrasound revealed no abnormalities. In the following 1.5 years, he was readmitted to the hospital several times because of respiratory distress with temporary oxygen dependency. At the age of 12 , he is in the first grade of high school and he has a normal exercise tolerance. Physical examination at the age of 12 years showed a height below the third centile, a sitting height/ height ratio on the 90th centile, a chest circumference on the tenth centile, a hand length on the tenth centile and a foot length on the third centile. The chest radiograph showed a narrow thorax with short ribs, short sternum and a CTR of 0.42 .

\section{Case 7}

Male, brother of case 6, born at term as the fifth and last child. Prenatal ultrasound at 20 and $21+5$ week gestational age showed short femora and a small thorax. At birth weight was $3,510 \mathrm{~g}$ (25-50th centile). A small, narrow chest was noted at birth. He was intubated because of severe respiratory distress. Radiographs showed a very hypoplastic thorax with an abnormal rib configuration, elevated and horizontally oriented clavicles, an abnormal pelvic configuration with a trident appearance of the acetabular margins, and prematurely ossified capital femoral epiphyseal centers. Ophthalmic examination was not performed. Laboratory data showed high levels of direct bilirubin and mildly elevated liver enzymes. Despite mechanical ventilation with high oxygen concentration he developed progressive hypoxemia and at 5 weeks he died of respiratory insufficiency. At autopsy, a small thorax with short ribs 
and elevated clavicles was noted. The lungs were hypoplastic with atelectasis, interstitial fibrosis of the lungs and multiple signs of pulmonary hypertension. Microscopically, the liver revealed bile duct proliferation and portal tract fibrosis. Kidneys showed slight mesangial glomerular sclerosis. Ribs showed hyperplastic cartilage and hypoplastic bone trabecula.

\section{Case 8}

Female, 11 years old, born at term as the third and last child to healthy, unrelated parents. Her father originated from Italy, while her mother is Dutch. At the age of 3 years, she was evaluated because of a small chest. There was no history of respiratory problems. Physical examination showed a small and narrow thorax (chest circumference $42 \mathrm{~cm}$, <third centile) with a protuberant sternum. The hands and feet were small, respectively $9.8 \mathrm{~cm}$ (<third centile) and $14.0 \mathrm{~cm}$ (third to 25th centile). No hepatomegaly was present. Skeletal radiographs showed a small, narrow thorax with short horizontally oriented ribs, spiky protrusions at the lateral and medial edges of the acetabulum and short, dysplastic phalanges of the hands. Renal ultrasound revealed no abnormalities. At the age of 11 , she is doing well in school (primary school) and she has a normal exercise tolerance. Physical examination at the age of 11 years showed a height between the tenth and 25th centile, a sitting height/height ratio above the 97th centile, a chest circumference on the third centile and a hand and foot length below the third centile. The chest radiograph showed a narrow thorax with short, horizontally oriented ribs with elevated, horizontally oriented clavicles and a CTR of 0.54 .

\section{Case 9}

Male, born at term as the first of three children of healthy, unrelated Dutch parents. At birth, weight was 3,360 g (25-50th centile). A small chest and postaxial polydactyly of both hands and feet were noted. After birth, he experienced a brief period of respiratory problems. At the age of 3 months he was admitted because of respiratory distress. Skeletal radiographs showed a small thorax with short, broad, anteriorly expanded ribs, an abnormal pelvic configuration with bilateral ileal flaring and short long bones with wide metaphyses. During his first year of life, he suffered recurrent respiratory and feeding difficulties. Twice he suffered respiratory distress during surgery for his polydactyly, for which surgery had to be interrupted. At the age of 18 months, he suddenly died at home. Autopsy was not performed.

\section{Case 10}

Female, 8 years old, born at term as the first of two children to healthy, unrelated Dutch parents. Her birth weight was 3,400 g (25-50th centile). She developed respiratory distress immediately after birth and was noted to have a narrow chest. She required oxygen for 1.5 weeks. Skeletal radiographs showed a narrow thorax with short, horizontally oriented ribs and elevated clavicles and a CTR of 0.64 , short iliac bones with irregular ossification of the acetabulum and spiky protrusions and mildly shortened femoral bones. At 3 weeks she was discharged from the hospital. After remaining well for 2 months, she developed respiratory distress and feeding difficulties and was readmitted for 2 months. In the following year, she was readmitted to the hospital several times because of respiratory distress, nocturnal desaturation and feeding difficulties. She was treated with diuretics, supplementary oxygen, and nasogastric tube feeding. At the age of 8.5 months she developed respiratory failure due to a viral infection and was mechanically ventilated for a month. At the age of 22 months, a gastrostomy catheter was placed because of persistent feeding difficulties. At the age of 3.5 years, she developed volvulus of the sigmoid which was surgically corrected. She was on supplementary oxygen and diuretic therapy for 3.5 years. At the age of 8 years, she is doing well at school (primary school) and the gastrostomy catheter was removed. Her exercise tolerance is mildly impaired. Physical examination at the age of 8 years showed a height on the 25 th centile, a sitting height/height ratio on the 97 th centile, a chest circumference the on the tenth centile, a hand length on the 50th centile and a foot length between the 50th and 75th centile. The chest radiographs showed a narrow thorax with short ribs, elevated, straight clavicles and a CTR of 0.55 .

\section{Case 11}

Male, 5 years old, born prematurely $(35+4$ weeks) by cesarean section as the second and last child to healthy, unrelated Dutch parents. At birth, weight was 2,060 g (tenth centile). Prenatal routine ultrasound at 31 weeks gestational age showed short extremities. After birth, a narrow chest was noted. Skeletal radiographs showed a narrow thorax with short, horizontally oriented ribs and a CTR of 0.65 , short iliac bones with the typical trident appearance of the acetabula and relatively short long bones of the legs. Ophthalmic examination and abdominal and cardiac ultrasound revealed no abnormalities. At the age of 6 weeks an inguinal hernia was corrected under general anesthesia. Postoperatively, he developed tachypnea with signs of pulmonary edema on the chest $\mathrm{X}$-ray. This was treated with furosemide, supplementary 
oxygen, and fluid restriction. In the following months, while on maintenance diuretic therapy and supplementary oxygen, he still had recurrent episodes of mild pulmonary edema during viral respiratory infections. Diuretics and oxygen were given until the age of 21 months. At the age of 5 years, old he is doing well at school, but he has an impaired exercise tolerance and still needs intermittent oxygen during viral respiratory infections. Physical examination at the age of 5 years showed a height on the 25 th centile, a sitting height/height ratio above the 97 th centile, a chest circumference between the 25 th and 50th centile, a hand length on the 50th centile and a foot length on the 75th centile. The chest radiograph showed a narrow thorax with short ribs, elevated, straight clavicles, and a CTR of 0.53 .

\section{Case 12}

Male, 5 years old, born at term, as the third and last child to healthy, unrelated Dutch parents. Prenatal routine ultrasound at 30 weeks gestational age showed short humeri and femora. His birth weight was $2,615 \mathrm{~g}$ (tenth to 25 th centile). Physical examination revealed no abnormalities and he was discharged after 1 day. At 14 months, he was evaluated because of limb shortness, a small, narrow chest (Fig. 1), and frequent periods of upper respiratory tract infection with respiratory distress. Skeletal radiographs showed a hypoplastic thorax, with short, horizontally oriented ribs,

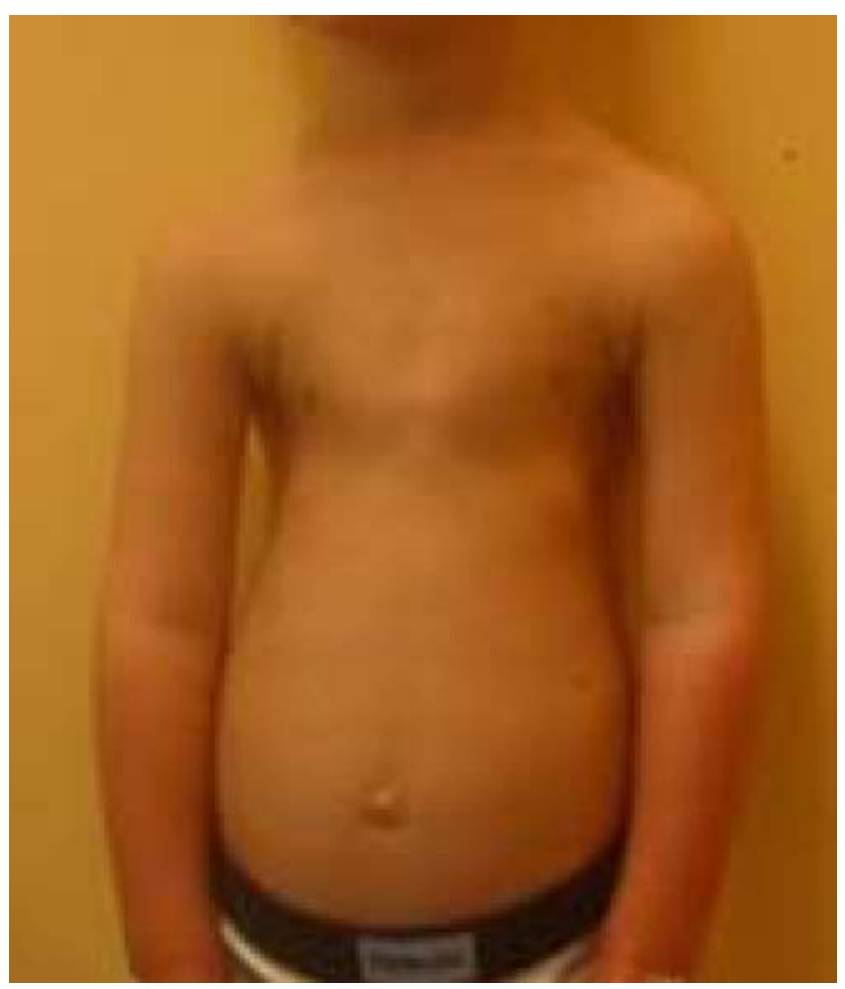

Fig. 1 Patient 12 at 5 years of age. Note the narrow chest elevated, horizontally oriented clavicles, CTR of 0.63 , short iliac bones with the typical trident appearance of the acetabula (Fig. 2), and shortened femoral bones. Ophthalmic examination and abdominal ultrasound revealed no abnormalities. At 5 years of age, he is doing well at school and has a normal exercise tolerance. Physical examination at the age of 5 years showed a height on the tenth centile, a sitting height/height ratio above the 97 th centile, a chest circumference on the tenth centile, a hand and foot length on the tenth centile. The chest radiograph showed a narrow thorax with short, horizontally oriented ribs with highly oriented clavicles, and a CTR of 0.60 (Fig. 3)

\section{Case 13}

Male infant, 9 months old, born at term as the second and last child to healthy, unrelated Dutch parents. Prenatal routine ultrasound had shown short femora. At birth weight was $4,150 \mathrm{~g}$ ( $>90$ th centile). A narrow chest, mildly shortened limbs and postaxial polydactyly type B of the left hand, which was removed shortly thereafter, were noted. He experienced mild respiratory symptoms for 4 days. Skeletal radiographs showed a narrow thorax, short ribs, long clavicles, and a small pelvis, with short iliac bones and a trident appearance of the acetabular margins. The hands showed short and dysplastic phalanges (Fig. 4). In the first months, he was admitted several times because of respiratory distress and feeding difficulties. Physical examination at the age of 9 months showed a height below the third centile, a

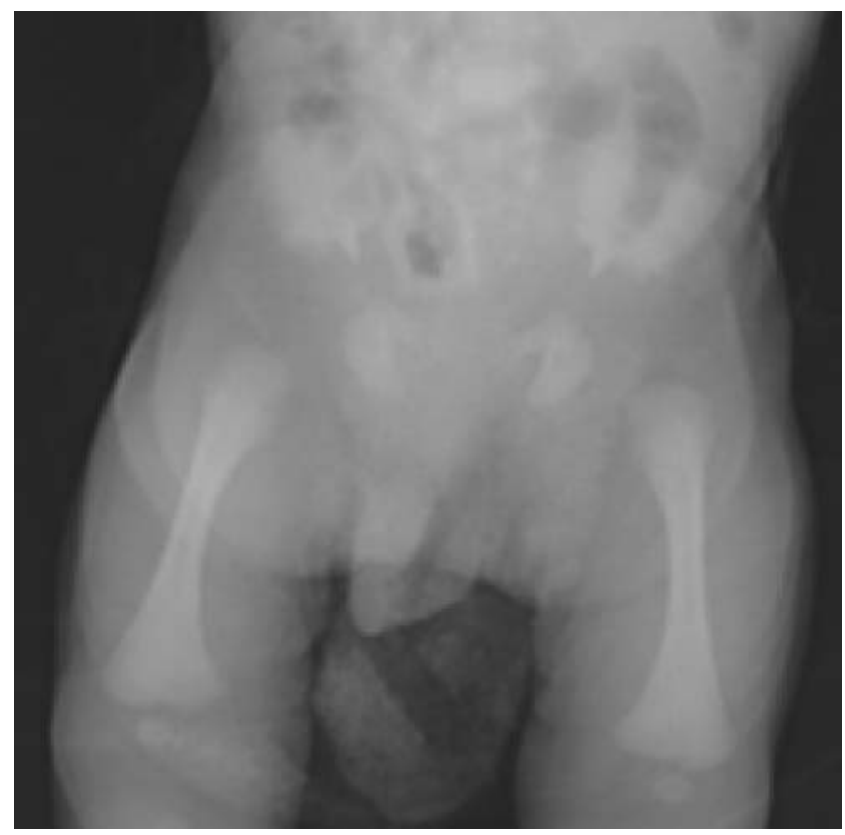

Fig. 2 X-ray of the pelvis of patient 12 shortly after birth. Note the typical trident appearance of the acetabula 


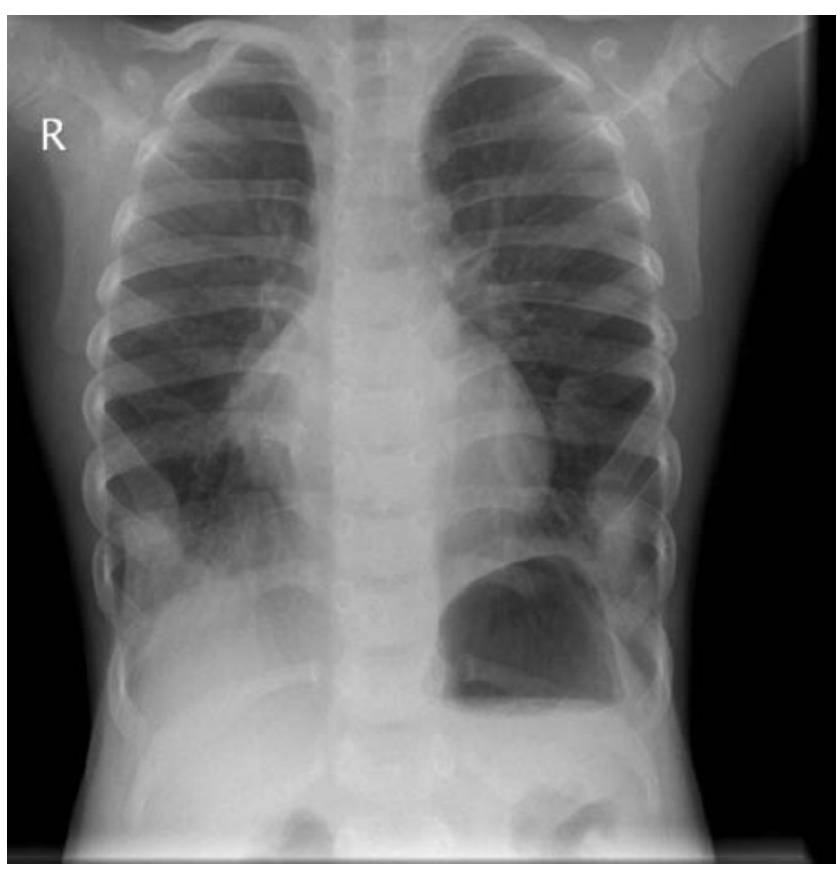

Fig. 3 Chest X-ray of patient 12 at 5 years of age. Note the narrow thorax and short ribs

sitting height/height ratio above the 97 th centile, a chest circumference below the third centile, a hand length on the tenth centile and a foot length below the third centile. The chest radiograph showed a narrow thorax with short ribs, highly oriented clavicles, and a CTR of 0.63 (Fig. 5). From 12 to 24 months of age, he suffered from increasing respiratory distress during viral respiratory infections. Twice he had to be intubated and mechanically ventilated. In the first episode, it was very difficult to wean him from the ventilator, while the second time weaning appeared impossible. On the parent's request, it was decided to

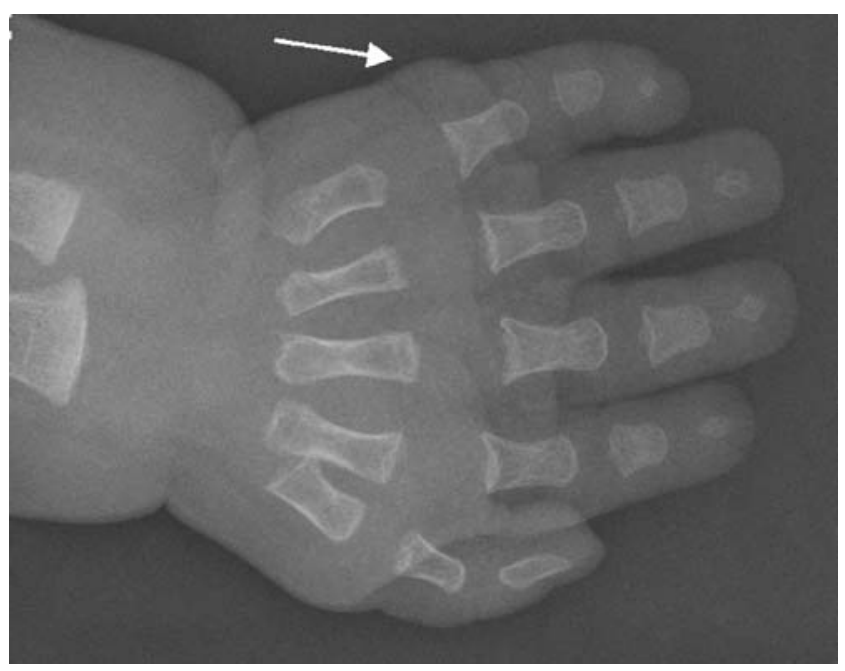

Fig. 4 X-ray of the left hand of patient 13 at the age of 4 months. Note short and dysplastic phalanges and the remainings of the postaxial polydactyly type B (arrow)

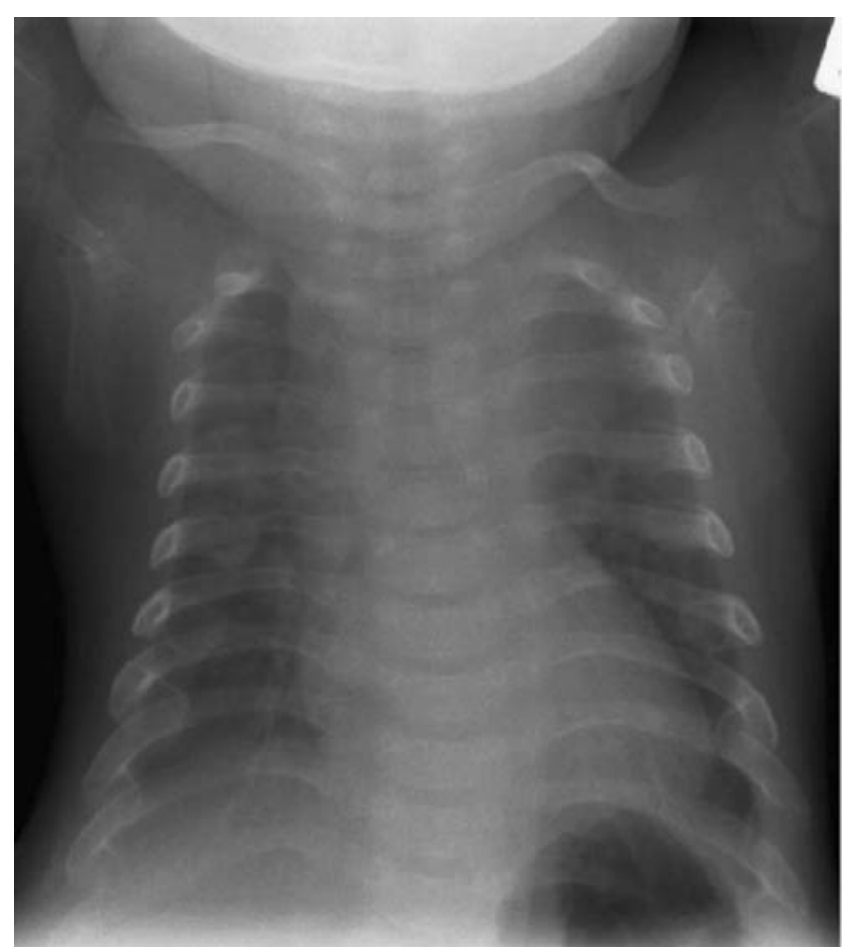

Fig. 5 Chest X-ray of patient 13 at the age of 6 months. Note the narrow thorax, short ribs and elevated clavicles

withdraw life-sustaining treatment. Permission for autopsy was not granted.

\section{Results of physical examination and additional investigations}

\section{Physical examination}

All patients had a small thorax and variable limb shortness and in almost all patients both liver and spleen were palpable below the costal margins. The anthropometric measurements (Figs. 6 and 7) revealed that the height of almost all patients was below the 50th centile, the sitting height/height ratio above the 90th centile and the chest circumference below the 50th centile. Hand- and foot length were also below the 50th centile in most patients, being below the third centile in some [19].

\section{Chest radiograph}

Chest radiograph showed a typical appearance in all patients: a narrow thorax with short, horizontally oriented ribs. Some patients had a strikingly short sternum and half of the patients had an abnormal shape and/or position of the clavicles. CTR was 0.50 or higher in nine of 11 patients; no relation was seen between CTR and the severity of respiratory problems. In the five cases 


\section{Anthropometrics}

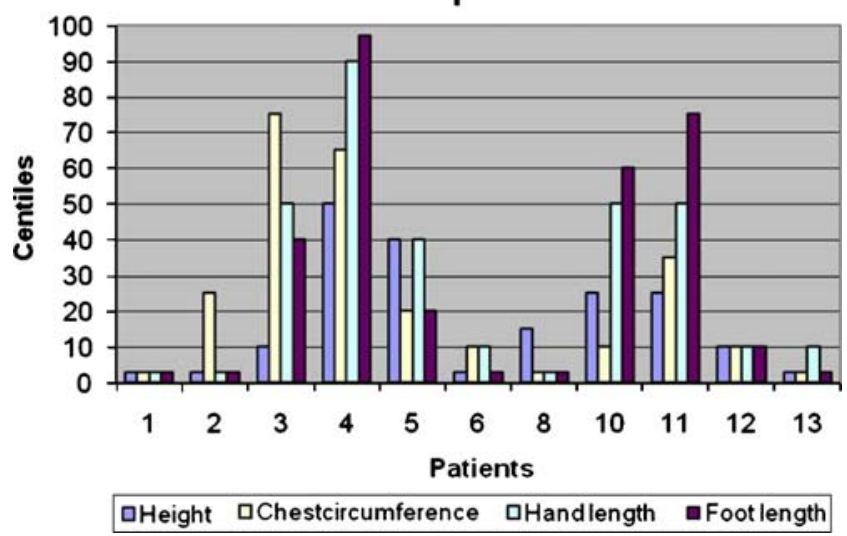

Fig. 6 Anthropometrics. The chest circumference of patient 3 is on the 75th centile, but it should be take into consideration her weightheight ratio was above the 90th centile

in which an earlier CTR was available, it improved over time.

\section{Abdominal ultrasound}

Abdominal ultrasound was normal in all examined patients except three. In case 1, it showed dilated intrahepatic bile ducts; in case 3, irregularly increased parenchymatous density of the liver and in case 4 , an extrarenal pyelum on the right side and a mass in the pancreas. The mass in the pancreas was also seen on an earlier ultrasound and was unchanged in diameter.

\section{Laboratory examination}

Laboratory examination revealed no abnormalities, except liver function abnormalities in case 3: AF $205 \mathrm{U} / 1$ (reference $<120 \mathrm{U} / \mathrm{l})$ ), ASAT $130 \mathrm{U} / 1$ (reference $<40 \mathrm{U} / \mathrm{l}$ ), ALAT 206 $\mathrm{U} / 1$ (reference $<45 \mathrm{U} / 1), \gamma$-GT $134 \mathrm{U} / 1$ (reference $<35 \mathrm{U} / 1$ ), LD $619 \mathrm{U} / 1$ (reference<450 U/1). A liver biopsy revealed inflammation of the portal triangles, predominantly eosin-

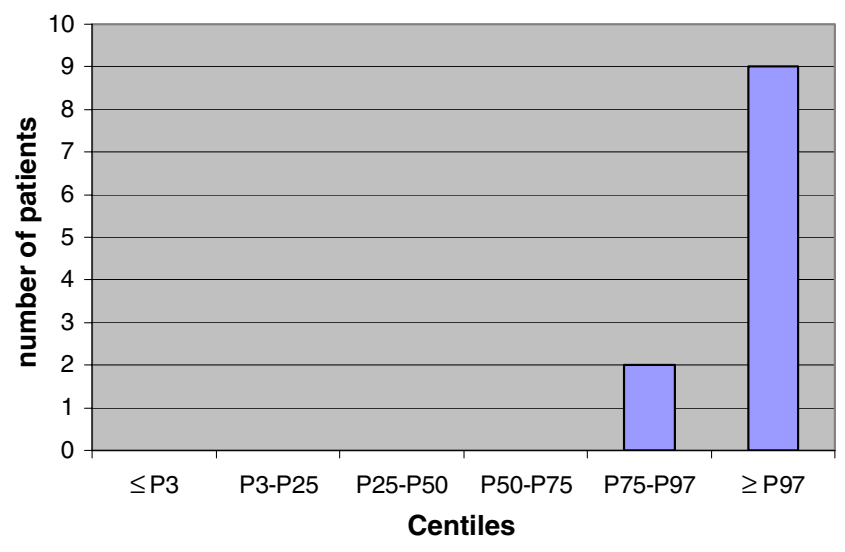

Fig. 7 Sitting height/height ratio centiles ophilic, and mild portoportal fibrosis without involvement of the bile canaliculi. Treatment with ursodeoxycholic acid after 6 months partially reversed the increased enzyme levels (AF 178 U/l; ASAT 45 U/l ALAT 57 U/l; $\gamma$-GT 21 $\mathrm{U} / 1 ; \mathrm{LD} 631 \mathrm{U} / \mathrm{l})$.

In none of the probands an IFT80 mutation was found on sequencing (case 9 and 13 were not analyzed).

Ophthalmic examination

Ophthalmic examination revealed narrow blood vessels in patient 1 , without visual impairment.

\section{Spirometry}

Only the patients older than 5 years of age were tested, because spirometry in younger patients is technically insufficient. A diminished FVC with a normal FEV1/FVC ratio was seen in all tested patients.

\section{Discussion}

Asphyxiating thoracic dystrophy (Jeune syndrome) is characterized by a small, narrow chest and variable limb shortness. The diagnosis is based on clinical and radiologic findings. All our patients fulfill the diagnostic criteria for ATD. The most consistent and characteristic findings were the abnormalities of the thorax and pelvis. The radiographic findings are so typical that distinction from other skeletal dysplasias, except Ellis-van Creveld syndrome, is not difficult $[30,33]$. In Ellis-van Creveld syndrome the appearance of the pelvis is indistinguishable, but the involvement of the thorax is less pronounced [22, 33]. Characteristic for Ellis-van Creveld syndrome are the ectodermal dysplasia, postaxial or axial polydactyly of the hands (constant feature) and sometimes feet, severe hypoplasia of fingers, slanting proximal tibial metaphyses, abnormal shape and size of the carpal bones, and heart defects in up to $50 \%$ of cases $[6,30,34]$. Renal failure is not seen in Ellis-van Creveld syndrome. Ellis-van Creveld syndrome is caused by mutations in the genes $E V C 1$ and 2 on chromosome 4p16 [34]. Several complications of ATD have been described in the literature. The respiratory problems are the main concern in ATD. A large percentage of the children with ATD die as a result of these problems. Percentages up to $80 \%$ have been mentioned in literature $[2,29,31]$. In our series, 11 of 13 cases experienced respiratory problems in the first 2 years of their lives, and two died because of these. Another patient died at home at the age of 18 months, but the cause of death was unknown. Ten out of 13 patients survived with varying degrees of medical support. Past the age of 2 years, respiratory 
problems resolved except in cases 8 and 11, who still required oxygen. The thoracic malformation tends to become less pronounced with age $[16,20-22,30]$. A plausible explanation could be the improved mechanical properties of the chest wall with growth. The prognosis of children with ATD seems better than described in most articles due to improved intensive care modalities. It is unlikely that our series is biased towards milder cases since the regional NICU is in our hospital as are the regional prenatal diagnostic services and cases with IFT80 mutations are not more severely affected [5]. So it seems very worthwhile to treat these children with all means in order to overcome their first difficult years. Due to the thoracic malformation and the resulting lung hypoplasia most children maintained a restrictive lung function impairment, but only four of them suffer clinical problems. In the long term, patients seem to live a relatively normal life. In our series, the two oldest patients have normal jobs and normal social life. CTR was 0.50 or higher in nine of 11 patients; no relation was seen between CTR and the severity of respiratory problems. For aesthetic reasons, one patient had reconstructive surgery of his thorax, with a satisfying result. His lung function is still mildly restricted. Several surgical techniques have been described in literature with varying results $[10-12,36,37]$. Renal complications are another complication seen in children with ATD. Usually renal problems do not appear until after the second year of life [9, 17]. Characteristic are tubular disorders such as a concentrating defect, a defect in the phosphate- and urate resorption, and proteinuria. Predominant histological findings described in literature are: atrophic and cystic dilatation of the tubules, diffuse interstitial fibrosis, periglomerular fibrosis, and glomerular sclerosis (nephronophthisis) $[14,15,17,18,25,32,35,39]$. Up to now, only one of our patients (case 1) experienced renal insufficiency. Her kidneys showed the histological abnormalities described above. Autopsy in case 7 revealed slight mesangial glomerular sclerosis. Though renal problems are uncommon in this series of patients, in literature, percentages up to $30 \%$ have been described [22]. Some of our patients are still young and renal problems might still develop later in life. Because renal complications tend to develop insidiously, renal function must be monitored regularly in patients with ATD. Since the first symptom of renal dysfunction often is a concentration defect [15] we recommend to monitor urine osmolality in first-voided urine in the morning and a desmopressine test if necessary. In the past occasionally, cases with ocular abnormalities have been described, usually retinitis pigmentosa $[1,3]$. The most characteristic and consistent finding on fundus examination has been described as a mid-peripheral zone of retinal pigment epithelial disturbance [41]. This can be seen as early as 5 years of age. Clinically, night blindness is the first symptom [1, 7]. All surviving patients underwent expert ophthalmic examination to look for abnormalities and in particular retinitis pigmentosa. No abnormalities except narrow blood vessels in patient 1 were seen. Very frequent ophthalmic examination does not seem necessary. Hepatic abnormalities have primarily been reported on post mortem examinations and liver biopsy specimens. Clinical symptoms of liver dysfunction are quite infrequent. Vomiting, hyperbilirubinemia, elevated transaminases, hepatomegaly, and portal hypertension have all been described $[23,27,40,42]$. The most frequently reported histopathological abnormalities are bile duct proliferation at the periphery of portal tracts and fibrosis ranging from mild portal fibrosis to cirrhosis [23, 27, 40, 42]. Liver pathology is more severe in older patients, suggesting that the histopathologic changes are progressive. However, the pathology findings in two patients of very different age in this series point to the variability of these changes. Routine laboratory examination in our population revealed elevated

Table 2 Recommendations for follow-up

\begin{tabular}{|c|c|c|c|c|c|}
\hline $\begin{array}{l}\text { Age } \\
\text { (years) } \\
\text { Diagnosis }\end{array}$ & $\begin{array}{l}\text { Physical examination } \\
\text { At diagnosis }\end{array}$ & $\begin{array}{l}\text { Laboratory tests (blood/ } \\
\text { urine) } \\
\text { At diagnosis }\end{array}$ & $\begin{array}{l}\text { Radiology } \\
\text { Skeletal survey, incl chest, abdominal } \\
\text { ultrasound }\end{array}$ & Spirometry & $\begin{array}{l}\text { Ophthalmic } \\
\text { examination } \\
\text { At diagnosis }\end{array}$ \\
\hline $0-2$ & $\begin{array}{l}\text { Frequently (every few } \\
\text { months) }\end{array}$ & Twice a year & Abdominal ultrasound at 2 years & & On indication \\
\hline $2-5$ & Twice a year & Every year & Abdominal ultrasound at 5 years & & $\begin{array}{l}\text { At the age of } \\
5 \text { years }\end{array}$ \\
\hline $5-10$ & Every year & Every year & Abdominal ultrasound at 10 years & Every year & $\begin{array}{l}\text { At the age of } \\
10 \text { years }\end{array}$ \\
\hline $10-15$ & Every year & Every year & Abdominal ultrasound at 15 years & Every year & On indication \\
\hline$>15$ & On indication & On indication & On indication & $\begin{array}{l}\text { On } \\
\text { indication }\end{array}$ & On indication \\
\hline
\end{tabular}

Laboratory tests: renal function (blood and urine; $24 \mathrm{~h}$ collected and fasting osmolality), and liver function (blood) 
liver enzymes in only one patient. Treatment with ursodeoxycholic acid was beneficial and reversed enzyme levels, as reported by others [27], but the effect on the prognosis of liver disease remains uncertain. Enzyme elevations preceded changes seen on ultrasound. This suggests that for purposes of monitoring liver disease, routine follow-up of liver enzymes is more sensitive than ultrasonography. Pancreatic complications have rarely been described [26]. Some studies have described microscopic cystic changes in the pancreatic ducts and pancreatic exocrine insufficiency is a rare complication in older patients with ATD [38]. An asymptomatic cystic lesion was found in case 4 .

In conclusion, ATD is a genetically heterogeneous multi-organ disease with variable expression, predominantly affecting the thoracic cage with respiratory complications as the main problem. Children often need respiratory assistance during their first years, but the respiratory problems decrease with age. The prognosis of ATD in our series seems better than described in literature and this justifies intensive treatment of respiratory complications in the first years of life.

A proposed follow-up protocol for different age groups is given in Table 2. It is based on this retrospective study and the literature. Since it is a first attempt, we have remained at the safe side. Identifying co-morbidity is the main purpose of the follow-up. Since in the first 2 years of life patients may experience severe respiratory problems, they should be seen frequently by a specialized pediatrician in a tertiary center. From the age of 2 years, the frequency can be decreased, depending on the patient's clinical condition. Laboratory examination of urine and blood should be done twice a year during the first 2 years and thereafter every year, abdominal ultrasound at ages 2, 5, 10, and 15 years, spirometry every year from the age of 5 years and ophthalmic examination at the age of 5 and 10 years. Regularly, evaluation of this follow-up protocol based on prospective evaluation of cases is necessary for its fine tuning.

Acknowledgments We thank all patients and their parents for their very helpful cooperation. Also, we thank I. Stolte-Dijkstra, clinical geneticist from the University Medical Center Groningen for her help with case 1 .

\section{Competing interests none.}

Open Access This article is distributed under the terms of the Creative Commons Attribution Noncommercial License which permits any noncommercial use, distribution, and reproduction in any medium, provided the original author(s) and source are credited.

\section{References}

1. Allen AW Jr, Moon JB, Hovland KR, Minckler DS (1979) Ocular findings in thoracic-pelvic-phalangeal dystrophy. Arch Ophthalmol 97:489-492
2. Amirou M, Bourdat-Michel G, Pinel N et al (1998) Brief report: successful renal transplantation in Jeune syndrome type 2. Pediatr Nephrol 12:293-294. doi:10.1007/s004670050456

3. Bard LA, Bard PA, Owens GW, Hall BD (1978) Retinal involvement in thoracic-pelvic-phalangeal dystrophy. Arch Ophthalmol 96:278-281

4. Barnes ND, Hull D, Simons JS (1969) Thoracic dystrophy. Arch Dis Child 44:11-17. doi:10.1136/adc.44.233.11

5. Beales PL, Bland E, Tobin JL et al (2007) IFT80, which encodes a conserved intraflagellar transport protein, is mutated in Jeune asphyxiating thoracic dystrophy. Nat Genet 39:727-729. doi:10.1038/ng2038

6. Brueton LA, Dillon MJ, Winter RM (1990) Ellis-van Creveld syndrome, Jeune syndrome, a renal-hepatic-pancreatic dysplasia: separate entities or disease spectrum? J Med Genet 27:252-255. doi:10.1136/jmg.27.4.252

7. Casteels I, Demandt E, Legius E (2000) Visual loss as the presenting sign of Jeune syndrome. Eur J Paediatr Neurol 4:243247. doi:10.1053/ejpn.2000.0313

8. Chen CP, Lin SP, Liu FF et al (1996) Prenatal diagnosis of asphyxiating thoracic dysplasia (Jeune syndrome). Am J Perinatol 13:495-498. doi:10.1055/s-2007-994435

9. Cortina H, Beltran J, Olague R et al (1979) The wide spectrum of the asphyxiating thoracic dysplasia. Pediatr Radiol 8:93-99. doi:10.1007/BF00973998

10. Davis JT, Ruberg RL, Leppink DM et al (1995) Lateral thoracic expansion for Jeune's asphyxiating dystrophy: a new approach. Ann Thorac Surg 60:694-696. doi:10.1016/0003-4975(95)92703-O

11. Davis JT, Heistein JB, Castile RG et al (2001) Lateral thoracic expansion for Jeune's syndrome: midterm results. Ann Thorac Surg 72:872-878. doi:10.1016/S0003-4975(01)02841-7

12. Davis JT, Long FR, Adler BH et al (2004) Lateral expansion for Jeune syndrome: evidence of rib healing and new bone formation. Ann Thorac Surg 77:445-448. doi:10.1016/S0003-4975(03)01340-7

13. den Hollander NS, Robben SGF, Hoogeboom AJM et al (2001) Early prenatal sonographic diagnosis and follow-up of Jeune syndrome. Ultrasound Obstet Gynecol 18:378-383. doi:10.1046/ j.0960-7692.2001.00530.x

14. Donaldson MDC, Warner AA, Trompeter RS et al (1985) Familial juvenile nephronophtisis, Jeune's syndrome, and associated disorders. Arch Dis Child 60:426-434. doi:10.1136/adc.60.5.426

15. Edelson PJ, Spackman TJ, Belliveau RE, Mahoney MJ (1974) A renal lesion in asphyxiating thoracic dysplasia. Birth Defects Orig Artic Ser X(4):51-56

16. Friedman JM, Kaplan HG, Hall JG (1975) The Jeune syndrome (asphyxiating thoracic dystrophy) in an adult. Am J Med 59:857862. doi:10.1016/0002-9343(75)90472-6

17. Giorgi PL, Gabrielli O, Bonifazi V et al (1990) Mild form of Jeune syndrome in two sisters. Am J Med Genet 35:280-282. doi:10.1002/ajmg.1320350227

18. Gruskin AB, Baluarte HJ, Cote ML, Elfenbein IB (1974) The renal disease of thoracic asphyxiant dystrophy. Birth Defects Orig Artic Ser X(4):44-50

19. Hall JG, Froster-Iskenius UG, Allanson JE (2003) Handbook of normal physical measurements. Oxford University Press, New York

20. Hanissian AS, Riggs WW Jr, Thomas DA (1967) Infantile thoracic dystrophy - a variant of Ellis-Van Creveld syndrome. J Pediatr 71:855-864. doi:10.1016/S0022-3476(67)80011-8

21. Hennekam RCM, Beemer FM, Gerards LJ, Cats B (1983) Thoracic pelvic phalangeal dystrophy (Jeune syndroom). Tijdschr Kindergeneeskd 51:95-100

22. Herdman RC, Langer LO (1968) The thoracic asphyxiant dystrophy and renal disease. Am J Dis Child 116:192-201

23. Hudgins L, Rosengren S, Treem W, Hyams J (1992) Early cirrhosis is survivors with Jeune thoracic dystrophy. J Pediatr 120:754-756. doi:10.1016/S0022-3476(05)80241-0 
24. Jeune M, Béraud C, Carron R (1955) Dystrophie thoracique asphyxiante de caractère familial. Arch Fr Pediatr 12:886-891

25. Kajantie E, Andersson S, Kaitila I (2001) Familial asphyxiating thoracic dysplasia: clinical variability and impact of improved neonatal intensive care. J Pediatr 139:130-133. doi:10.1067/ mpd.2001.114701

26. Karjoo M, Koop CE, Cornfield D, Holtzapple G (1973) Pancreatic exocrine enzyme deficiency associated with asphyxiating thoracic dystrophy. Arch Dis Child 48:143-146. doi:10.1136/adc.48.2.143

27. Labrune P, Fabre M, Trioche P et al (1999) Jeune syndrome and liver disease: report of three cases treated with ursodeoxycholic acid. Am J Med Genet 87:324-328. doi:10.1002/(SICI)1096-8628 (19991203)87:4<324::AID-AJMG8>3.0.CO;2-U

28. Lameer-Engel G, Martijn A (2003) Werkboek kinderradiologie. VU uitgeverij, Amsterdam

29. Morgan NV, Bacchelli C, Gissen P et al (2003) A locus for asphyxiating thoracic dystrophy, ATD maps to chromosome 15q13. J Med Genet 40:431-435. doi:10.1136/jmg.40.6.431

30. Oberklaid F, Danks DM, Mayne V, Campbell P (1977) Asphyxiating thoracic dysplasia: clinical, radiological, and pathological information on 10 patients. Arch Dis Child 52:758-765. doi:10.1136/ adc. 52.10 .758

31. O'Connor MB, Gallagher DP, Mulloy E (2008) Jeune syndrome. Postgrad Med J 84:559. doi:10.1136/pgmj.2007.066159

32. Özçay F, Derbent M, Demirhan B et al (2001) A family with Jeune syndrome. Pediatr Nephrol 16:623-626. doi:10.1007/ s004670100627

33. Pirnar T, Neuhauser EBD (1966) Asphyxiating thoracic dystrophy of the newborn. Am J Roentgen 98:358-364
34. Ruiz-Perez VL, Tompson SW, Blair HJ et al (2003) Mutations in two nonhomologous genes in a head-to-head configuration cause Ellis-van Creveld syndrome. Am J Hum Genet 72:728-732. doi: $10.1086 / 368063$

35. Shah KJ (1980) Renal lesion in Jeune's syndrome. Br J Radiol 53:432-436

36. Sharoni E, Erez E, Chorev G et al (1998) A chest reconstruction in asphyxiating thoracic dystrophy. J Pediatr Surg 33:1578-1581. doi:10.1016/S0022-3468(98)90505-X

37. Todd DW, Tinguely SJ, Norberg WJ (1986) A thoracic expansion technique for Jeune's asphyxiating thoracic dystrophy. J Pediatr Surg 21:161-163. doi:10.1016/S0022-3468(86)80073-2

38. Turkel SB, Diehl EJ, Richmond JA (1985) Necropsy findings in neonatal asphyxiating thoracic dystrophy. J Med Genet 22:112118. doi:10.1136/jmg.22.2.112

39. van der Heijden AJ, Schröder CH, Van Wij JAE (2001) Werkboek kindernefrologie. VU uitgeverij, Amsterdam

40. Whitley CB, Schwarzenberg SJ, Burke BA et al (1987) Direct hyperbilirubinemia and hepatic fibrosis: a new presentation of Jeune syndrome (asphyxiating thoracic dystrophy). Am J Med Genet Suppl 3:211-220. doi:10.1002/ajmg.1320280525

41. Wilson DJ, Weleber RG, Beals RK (1987) Retinal dystrophy in Jeune's syndrome. Arch Ophthalmol 105:651-657

42. Yerian LM, Brady L, Hart J (2003) Hepatic manifestations of Jeune syndrome (asphyxiating thoracic dystrophy). Semin Liver Dis 23:195-200. doi:10.1055/s-2003-39950

43. Zimmer EZ, Weinraub Z, Raijman A et al (1984) Antenatal diagnosis of a fetus with an extremely narrow thorax and short limb dwarfism. J Clin Ultrasound 12:112-114. doi:10.1002/ jcu. 1870120213 